\title{
Pronuclear development and the first cleavage division in polyspermic mouse eggs
}

\author{
Anna Witkowska \\ Department of Embryology, Zoological Institute, University of Warsaw, 00-927 Warsaw, \\ Poland
}

\begin{abstract}
Summary. Zona-free $\mathrm{F}_{1}(\mathrm{C} 57 \mathrm{~B} 1 / 10 \times \mathrm{CBA} / \mathrm{H})$ mouse eggs were fertilized in vitro with $F_{1}$ spermatozoa and examined in whole mounts $4 \cdot 5-5 \mathrm{~h}$ or $17-19 \mathrm{~h}$ after mixing the gametes. The fertilization rate was nearly $90 \%$ with about one-third of eggs undergoing monospermic and two-thirds polyspermic fertilization (2-8 spermatozoa). In all monospermic eggs the sperm head developed into a large pronucleus. In polyspermic eggs either all or only some of the spermatozoa had completed the process of transformation, while the remainder were arrested at the early phase of pronuclear development. During the first cleavage division these pronuclei condensed but separate chromosomes did not differentiate and therefore could not contribute to the genome of the embryo. The condensed pronuclei were passively displaced to one or both blastomeres. The number of decondensed sperm heads present in the egg shortly after fertilization was therefore not always equivalent to the ploidy of the future embryo. The duration of the first cell cycle appeared to be related to ploidy (number of functional = 'advanced' pronuclei), with the monospermic eggs dividing first.
\end{abstract}

\section{Introduction}

In vivo, the rate of polyspermy is low and this anomaly most frequently occurs as dispermy with subsequent triploidy. Under in-vitro conditions, when the cumulus cells and the zona pellucida are removed and a high concentration of spermatozoa is used, up to $80 \%$ of eggs can undergo polyspermic fertilization. The rate of polyspermy depends on a wide range of experimental variables, e.g. concentration and time of preincubation of spermatozoa, age of eggs and the genotype of gametes (Wolf, Inoue \& Stark, 1976; Kaleta, 1977; Wolf, 1978). In contrast to these studies, which were primarily concerned with physiological aspects of egg-sperm interactions in polyspermic fertilization, the experiments presented here examine the whole process of transformation of spermatozoa into male pronuclei and follow their fate up to the first cleavage division.

\section{Materials and Methods}

The mice used were F1 (C57BL/10 $\times \mathrm{CBA} / \mathrm{H})$ hybrids. Females about 3 months old were injected intraperitoneally with 10 i.u. PMSG followed by $10 \mathrm{i} . \mathrm{u}$. hCG $48 \mathrm{~h}$ later. Ova were picked out from the ampulla and placed in hyaluronidase (200 i.u. in Ringer's solution). After removal of the follicle cells, eggs of normal appearance were identified by observation under the 
dissecting microscope and selected for further use. To dissolve the zona pellucida, eggs were transferred to the fertilization medium (Toyoda, Yokoyama \& Hosi, 1971) as modified by Kaleta (1977) containing $\alpha$-chymotrypsin at a concentration of $0.003 \%$ (9000 ATEE units $/ \mathrm{mg}$ : Koch-Light). As soon as the zona pellucida started to dissolve the eggs were placed in enzyme-free medium where the membrane was finally removed by pipetting. After thorough washing the eggs were pooled in drops of fertilization medium.

The contents of the epididymides and vasa deferentia from an adult male mouse were squeezed into a drop of fertilization medium under liquid paraffin. The suspension of spermatozoa was incubated at $37^{\circ} \mathrm{C}$ in an atmosphere of $5 \% \mathrm{CO}_{2}$ in air for up to $1 \mathrm{~h}$ before transfer to drops of medium containing eggs. The final concentration of spermatozoa was about $8 \times 10^{5} / \mathrm{ml}$. At the time of mixing the gametes, the eggs were $15-19 \mathrm{~h}$ after hCG injection.

\section{Series $A$}

At $4.5-5 \mathrm{~h}$ after mixing the gametes, the eggs were removed by pipette from the sperm suspension and whole-mount haematoxylin preparations were made (Tarkowski, 1971).

The following stages of transformation of sperm heads were distinguished.

Stage I: the start of sperm head decondensation. This stage can only be observed very soon after sperm penetration, up to $2 \mathrm{~h}$ after gamete mixing, and was not encountered in eggs described in this study.

Stage II: a very early stage of pronucleus formation with the occasional appearance of nucleoli. The sperm head shape was oval or round (Pl. 1, Figs 2, 3 and 4).

Stage III: the pronucleus is formed with numerous but small nucleoli. Round shape, various sizes (Pl. 1, Figs 5 and 6). Fig. 7).

Stage IV: the pronucleus is large with numerous small and one or a few larger nucleoli (Pl. 1,

In 93 eggs the size of the female pronucleus and all sperm heads, regardless of stage of transformation, was measured in whole-mount preparations with the use of an ocular micrometer. Nuclear volume was calculated from the diameters obtained.

\section{Series $B$}

Eggs to be studied at the time of the first cleavage division were washed after $5 \mathrm{~h}$ and placed in culture medium (Whitten, 1971) until examination 12-14 h later (i.e. 17-19 $\mathrm{h}$ after mixing the gametes). Immediately after examination whole-mount preparations or air-dried preparations (Tarkowski, 1966) were made.

\section{Results}

The proportions of eggs fertilized were similar in Series A (89\%) and Series B (86\%).

\section{Series A: eggs examined $4 \cdot 5-5 \mathrm{~h}$ after gamete mixing}

About one-third of the eggs underwent monospermic fertilization while the others were penetrated by 2-8 spermatozoa (Table 1). Spermatozoa that penetrated the egg cytoplasm always decondensed but only some sperm nuclei underwent complete transformation into male pronuclei.

In all fertilized eggs the second polar body was extruded and a single female pronucleus was formed (Pl. 1, Fig. 1). In all monospermic eggs the male pronucleus attained Stage III or IV; these will be referred to as 'advanced' pronuclei (Table 4). In the majority of dispermic eggs $(52 / 66)$ both sperm nuclei had transformed into 'advanced' pronuclei; the remaining eggs contained a female and a male pronucleus and, in addition, a sperm nucleus arrested in Stage II. 
Table 1. Frequency (\%) of 1-cell mouse eggs penetrated by different numbers of spermatozoa

\begin{tabular}{|c|c|c|c|c|c|c|c|c|c|c|}
\hline \multirow[b]{3}{*}{ Series } & \multirow{3}{*}{$\begin{array}{l}\text { No. of } \\
\text { eggs }\end{array}$} & \multirow{3}{*}{$\begin{array}{c}\text { Monospermic } \\
\text { eggs }\end{array}$} & \multicolumn{8}{|c|}{ Polyspermic eggs } \\
\hline & & & \multicolumn{7}{|c|}{ No. of male pronuclei* } & \multirow{2}{*}{$\begin{array}{l}\text { Average no. of } \\
\text { spermatozoa/egg }\end{array}$} \\
\hline & & & 2 & 3 & 4 & 5 & 6 & 8 & Total & \\
\hline A & 204 & $31 \cdot 4$ & $32 \cdot 3$ & $17 \cdot 7$ & $9 \cdot 4$ & $6 \cdot 4$ & 1.9 & 0.9 & $68 \cdot 6$ & $2 \cdot 36$ \\
\hline B & $127 \dagger$ & $26 \cdot 0$ & $29 \cdot 1$ & 29.9 & $6 \cdot 3$ & $5 \cdot 5$ & $2 \cdot 4$ & 0.8 & $74 \cdot 0$ & 2.46 \\
\hline
\end{tabular}

* Includes fully grown pronuclei and sperm heads arrested at early stages of transformation.

$\dagger$ Includes eggs with groups of condensed chromosomes and 'arrested' pronuclei.

Table 2. Volume of female and male pronuclei in mouse eggs penetrated by different numbers of spermatozoa after incubation for $5 \mathrm{~h}$ (Series $\mathrm{A}$ )

\begin{tabular}{cccccc}
\hline & & & \multicolumn{3}{c}{ Mean volume $\left(\mu \mathrm{m}^{3}\right)$} \\
\cline { 5 - 6 } $\begin{array}{c}\text { No. of } \\
\text { penetrating } \\
\text { spermatozoa }\end{array}$ & $\begin{array}{c}\text { No. of } \\
\text { eggs }\end{array}$ & $\begin{array}{c}\text { Nodvanced' } \\
\text { male } \\
\text { pronuclei }\end{array}$ & $\begin{array}{c}\text { Female } \\
\text { pronucleus }\end{array}$ & $\begin{array}{c}\text { All male } \\
\text { pronuclei } \\
\text { per egg }\end{array}$ & $\begin{array}{c}\text { 'Advanced' } \\
\text { male } \\
\text { pronucleus }\end{array}$ \\
\hline 1 & 22 & 22 & 321.3 & 589.5 & 589.5 \\
2 & 31 & 51 & 347.2 & 774.3 & 461.5 \\
3 & 19 & 33 & 377.7 & 1106.8 & 583.5 \\
4 & 10 & 22 & 470.2 & 1333.9 & 506.9 \\
5 & 11 & 31 & 634.5 & 2070.1 & 621.6 \\
\hline
\end{tabular}

Table 3. Condition of mouse eggs examined at the time of the first cleavage division, $17-19 \mathrm{~h}$ after gamete mixing (Series B)

\begin{tabular}{|c|c|c|c|c|c|c|c|c|c|}
\hline \multirow{3}{*}{$\begin{array}{l}\text { Total } \\
\text { no. of } \\
\text { eggs }\end{array}$} & \multicolumn{7}{|c|}{ One-cell eggs } & \multirow[b]{3}{*}{$\begin{array}{c}\text { Cleaving } \\
\text { eggs }\end{array}$} & \multirow[b]{3}{*}{$\begin{array}{l}\text { 2-cell } \\
\text { embryos }\end{array}$} \\
\hline & & \multicolumn{3}{|c|}{ Pronucleate } & \multicolumn{3}{|c|}{ Condensed chromosomes } & & \\
\hline & No. & No. & $\begin{array}{l}\text { Mono- } \\
\text { spermic }\end{array}$ & $\begin{array}{l}\text { Poly- } \\
\text { spermic }\end{array}$ & No. & $\begin{array}{l}\text { Mono- } \\
\text { spermic }\end{array}$ & $\begin{array}{l}\text { Poly- } \\
\text { spermic }\end{array}$ & & \\
\hline \multirow[t]{2}{*}{$\begin{array}{l}229 \\
(\%)\end{array}$} & $\begin{array}{c}127 \\
(55 \cdot 5)\end{array}$ & $\begin{array}{c}98 \\
(42 \cdot 8)\end{array}$ & $\begin{array}{c}15 \\
(6 \cdot 5)\end{array}$ & $\begin{array}{c}83^{*} \\
(36 \cdot 2)\end{array}$ & $\begin{array}{c}29 \\
(12 \cdot 7)\end{array}$ & $\begin{array}{c}18 \\
(7.9)\end{array}$ & $\begin{array}{l}11 \dagger \ddagger \\
(4 \cdot 8)\end{array}$ & $\begin{array}{c}38 \S \\
(16 \cdot 6)\end{array}$ & $\begin{array}{c}649 \\
(27 \cdot 9)\end{array}$ \\
\hline & & & \multicolumn{7}{|c|}{$\begin{array}{l}\text { * } 30 \text { eggs with 'arrested' pronuclei. } \\
+10 \text { eggs were dispermic and } 1 \text { was trispermic. } \\
\ddagger 2 \text { eggs with one condensed 'arrested' pronucleus. } \\
\$ 1 \text { egg with one condensed 'arrested' pronucleus. } \\
\text { 1 embryo with } 3 \text { condensed male pronuclei. }\end{array}$} \\
\hline
\end{tabular}

In eggs penetrated by more than 2 spermatozoa at least one sperm head had developed into an 'advanced' pronucleus (Table 4). However, the incidence of eggs with all sperm heads which had developed into 'advanced' pronuclei decreased with the increasing level of polyspermy, and even in trispermic eggs was $<50 \%(15 / 36)$. If it is assumed that only 'advanced' pronuclei are functional pronuclei which contribute to the genome of the embryo (see below and 'Discussion'), it follows that each group of polyspermic eggs is, in fact, heterogeneous as regards the degree of effective polyspermy and potential ploidy increase. For instance, among the 19 tetraspermic eggs there were only 2 that contained 4 'advanced' pronuclei, while the remaining had 3,2 or 1 'advanced' pronuclei. 
Table 4. Pronuclear development in mouse eggs examined $5 \mathrm{~h}$ (Series A) and $17-19 \mathrm{~h}$ (Series B) after insemination

\begin{tabular}{|c|c|c|c|c|c|c|c|c|}
\hline \multirow[b]{2}{*}{ Series } & \multirow{2}{*}{$\begin{array}{l}\text { No. of } \\
\text { 'advanced' } \\
\text { pronuclei }\end{array}$} & \multicolumn{7}{|c|}{ No. of spermatozoa in egg } \\
\hline & & 1 & 2 & 3 & 4 & 5 & 6 & 8 \\
\hline \multirow[t]{8}{*}{ A } & 1 & 64 & 14 & 6 & 4 & 1 & 0 & 0 \\
\hline & 2 & & 52 & 15 & 9 & 3 & 2 & 0 \\
\hline & 3 & & & 15 & 4 & 3 & 0 & 0 \\
\hline & 4 & & & & 2 & 4 & 1 & 0 \\
\hline & 5 & & & & & 2 & 1 & 0 \\
\hline & 6 & & & & & & 0 & 1 \\
\hline & 7 & & & & & & & 1 \\
\hline & Total & 64 & 66 & 36 & 19 & 13 & 4 & 2 \\
\hline \multirow[t]{6}{*}{ B } & 1 & 33 & 1 & 3 & 0 & 0 & 0 & 0 \\
\hline & 2 & & 25 & 15 & 2 & 1 & 1 & 0 \\
\hline & 3 & & & 20 & 4 & 2 & 0 & 1 \\
\hline & 4 & & & & 2 & 0 & 1 & 0 \\
\hline & 5 & & & & & 4 & 1 & 0 \\
\hline & Total & 33 & 26 & 38 & 8 & 7 & 3 & 1 \\
\hline
\end{tabular}

The total volume of all male pronuclei, and the 'advanced' pronuclei only, increased with the degree of polyspermy (Table 2). The mean volume of an individual 'advanced' pronucleus, however, seemed to be independent of the number of spermatozoa penetrating the egg and the number of 'advanced' pronuclei present; it was similar to that of the single male pronucleus in monospermic eggs. This implies that the cytoplasmic materials required for pronuclear growth are present in the egg in excess and that, at least at the beginning of the cell cycle of the zygote, the size of individual 'advanced' pronuclei is regulated only by factors intrinsic to them.

The female pronucleus is morphologically similar in monospermic eggs and all types of polyspermic eggs, except that its volume increases as the degree of polyspermy increases (Table 2). This observation is very puzzling and difficult to interpret. One possible explanation is that the polyspermic eggs came from experiments in which fertilization occurred very quickly (or these eggs were the first to be fertilized in a batch), so that pronuclear development began earlier and resulted in larger size at the time of examination. Even so, it remains difficult to explain the evident relationship between the volume of the female pronucleus and the degree of polyspermy.

\section{Series B: eggs examined at first cleavage (17-19 h after insemination)}

At the time of examination $28 \%$ of eggs had undergone the first cleavage division (Table 3 ). Some of the remaining eggs were still pronucleate or contained separate haploid groups of chromosomes, and others were in mitosis (metaphase to telophase).

With the techniques used in this study it was not possible to determine the ploidy of 2-cell embryos or eggs in mitosis and, consequently, to distinguish monospermic from polyspermic eggs. This information was available, however, for 1-cell eggs. In comparison to eggs examined 5 $\mathrm{h}$ after insemination (Series A), the incidence of monospermic and dispermic eggs in Series B decreased slightly and the incidence of trispermic eggs increased (Table 1). These data, together with those presented in Table 3, provide clear evidence on two points. First, monospermic eggs started to cleave earlier than did polyspermic eggs. The incidence of monospermy was significantly higher among eggs with differentiated chromosomes than among pronucleate eggs $\left(\chi^{2}=23.0, P<0.001\right)$. Second, among polyspermic eggs those that were dispermic were the first to begin the first cleavage division (10 polyspermic eggs with condensed chromosomes were dispermic and only 1 was trispermic).

Since the time of examination coincided with the first cleavage division, the male nuclei in 1-cell eggs were in the final stage of their development. In many polyspermic pronucleate eggs 
PLATE 1

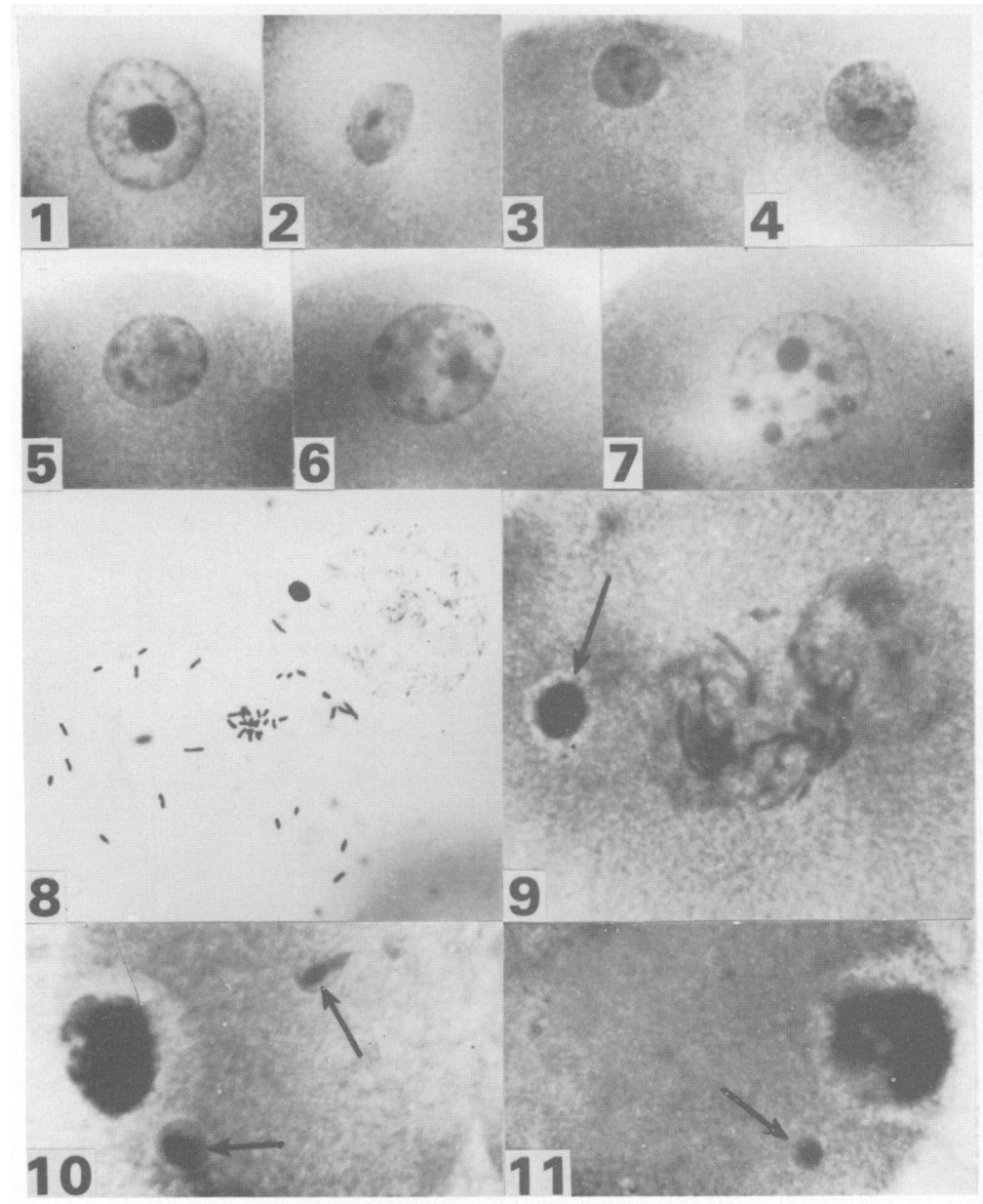

Figs 1-7. Formation of pronuclei in mouse eggs fixed $4.5-5 \mathrm{~h}$ after mixing the gametes (Series A). $\times 820$.

Fig. 1. Female pronucleus from an egg penetrated by 5 spermatozoa.

Figs 2, 3 and 4. Examples of sperm heads at Stage II of transformation.

Figs 5 and 6. Two male pronuclei at Stage III.

Fig. 7. Male pronucleus representing Stage IV.

Figs 8-11. Mouse eggs from Series B, 17-19 h after gamete mixing.

Fig. 8. Metaphase chromosomes (40) and one pronucleus at a very early stage of chromatin condensation. $\times 900$.

Fig. 9. Condensed 'arrested' pronucleus (arrow) in an egg penetrated by 3 spermatozoa. Of the 3 groups of chromosomes in prometaphase only one is in focus. $\times 1100$.

Figs 10 and 11. Fragments of blastomeres from a 2-cell embryo showing a large blastomere nucleus and condensed 'arrested' sperm nuclei (arrows). $\times 1100$. 
the pronuclei not only differed between themselves, as was already the case $5 \mathrm{~h}$ after insemination, but the differences in both structure and size were considerable. The frequencies of Series B eggs with different numbers of 'advanced' pronuclei, or with groups of condensed chromosomes, in monospermic eggs and various classes of polyspermic eggs, are shown in Table 4. The similarity of these data to those collected $5 \mathrm{~h}$ after insemination (Table 4) clearly demonstrates that the fate of male nuclei is fixed soon after fertilization, i.e. sperm nuclei that have not transformed into 'advanced' pronuclei by $5 \mathrm{~h}$ are irrevocably blocked at Stage II.

Some of the polyspermic eggs in which condensation of chromosomes had already begun also contained highly condensed small nuclei. These nuclei undoubtedly represent male nuclei that are arrested in early stages of transformation and do not participate in mitosis. As a result of cytokinesis they are passively displaced to one, or both, daughter blastomeres (P1. 1, Figs 10 and 11). Thus, at the time of first mitosis these nuclei are still able to react to cytoplasmic factors by condensation of chromatin, although individual chromosomes do not differentiate (Pl. 1, Fig. 9). In polyspermic eggs initiating the cleavage division, the degree of spiralization of chromosomes in particular 'advanced' pronuclei often differed and these differences were much more marked than those previously described in monospermic eggs (Donahue, 1972). An extreme case was found in an egg with a group of 40 chromosomes and a pronucleus in prophase (Pl. 1, Fig. 8).

\section{Discussion}

The results of the present study show that in polyspermic mouse eggs all sperm heads are decondensed, but that not all are transformed into large, functional pronuclei. This phenomenon has not been described previously, probably because the observations have not continued beyond the early pronuclear stages. The inability of some sperm nuclei to undergo transformation into functional pronuclei can not be due to the shortage of basic cytoplasmic materials required for pronuclear growth, because $5 \mathrm{~h}$ after insemination the mean volume of 'advanced' male pronuclei, even in excessively polyspermic eggs, is equal to that of the male pronucleus in monospermic eggs (Table 2).

This phenomenon might be explained by the gradual disappearance or inactivation of a specific egg cytoplasmic factor responsible for transformation of sperm heads into pronuclei (Usui \& Yanagimachi, 1976), together with non-simultaneous penetration of the egg by spermatozoa. As pointed out by Yanagimachi (1978) "... The fully activated state of the egg cytoplasm appears to be necessary not for the decondensation of sperm nucleus, but for the transformation of the decondensed nucleus into a functional sperm pronucleus". Thus, in eggs into which successive spermatozoa penetrated simultaneously, or within a short period of time, all may start pronuclear development at the same time and become functional pronuclei. On the other hand, when penetration is extended in time, spermatozoa that penetrate later may become arrested because the hypothetical factor has by this time disappeared or become inactivated. It is obvious that with higher numbers of penetrating spermatozoa the likelihood of simultaneous penetration decreases. If this explanation is correct, it would follow that the disappearance (inactivation) of the cytoplasmic factor occurs faster than the development of the block to polyspermy. The available data do not permit calculation of the duration of both processes, but other (unpublished) observations suggest that the completion of the polyspermy block occurs not later than $2 \mathrm{~h}$.

Comparison of the structure of pronuclei in eggs from Series A and B clearly shows that the sperm nuclei which have not transformed into true 'advanced' pronuclei by $5 \mathrm{~h}$ remain non-functional until the first cleavage division. These nuclei become highly condensed in eggs entering into mitosis, and do not appear to interfere with cleavage. The further fate of these nuclei remains unknown. In one observed 2-cell embryo, however, they remained condensed and looked pycnotic.

The inability of some spermatozoa to undergo complete transformation into functional 
pronuclei implies that the number of decondensed sperm heads present in the egg shortly after fertilization does not always define the degree of polyploidy of the future embryo. For example in the egg shown in Pl. 1, Fig. 9 one of the 3 male nuclei will remain non-functional and the egg would have entered mitosis with a triploid rather than a tetraploid set of chromosomes.

Although at the beginning of the 1-cell stage the growth of multiple 'advanced' pronuclei does not appear to be handicapped by their number, this is probably not true during the later phases of pronuclear development. Striking differences between the pronuclei in the degree of spiralization of chromosomes observed in some polyspermic eggs initiating the cleavage division suggest that pronuclear development does not proceed at a uniform pace. The developmental implications of this phenomenon are intriguing. One can speculate for instance, that in the dispermic egg shown in P1. 1, Fig. 8 the 'delayed' pronucleus (or a group of chromosomes eventually derived from it) cannot contribute to the common metaphase plate and would be passively displaced to one of the daughter blastomeres. During the next mitosis, however, such a haploid nucleus could contribute to the genome of this particular blastomere, thus leading to the formation of a diploid/triploid mosaic.

Observations on eggs examined at 17-19 $\mathrm{h}$ after gamete mixing strongly suggest that the duration of the first cell cycle is correlated with ploidy (= number of functional pronuclei), with monospermic (diploid) eggs dividing first, and dispermic (triploid and diploid) eggs dividing next. Although it cannot be excluded that some of the observed 2-cell embryos originated from eggs with higher degrees of polyspermy, it seems that at the time of examination the majority, if not all, of the highly polyspermic eggs were still pronucleate. Whether these eggs would ever have cleaved is unknown. That the duration of the first cell cycle may be related to ploidy has also been suggested by Tarkowski (1980), who observed that fertilized anucleate egg fragments tend to divide faster than sister nucleate fragments containing one more haploid set of chromosomes (maternal), and by Edwards (1958) who proposed that the delay in development of triploids and tetraploids in comparison with haploids and diploids "... must have occurred before cleavage began, i.e. in the pronuclear stages or during syngamy". However, there is no reason why the first cell cycle should be exceptional and one may speculate that in polyploid embryos all subsequent cycles are also prolonged.

I thank Professor A. K. Tarkowski for his criticism of the manuscript.

\section{References}

Donahue, R.P. (1972) Cytogenetic analysis of the first cleavage division in mouse embryos. Proc. natn. Acad. Sci. U.S.A. 69, 74-77.

Edwards, R. G. (1958) The number of cells and cleavages in haploid, diploid, polyploid and other heteroploid mouse embryos at $3 \frac{1}{2}$ days gestation. $J$. exp. Zool. 138, 189-207.

Kaleta, E. (1977) Influence of genetic factors on the fertilization of mouse ova in vitro. J. Reprod. Fert. 51, 375-381.

Tarkowski, A. K. (1966) An air-drying method for chromosome preparations from mouse eggs. Cytogenetics 5, 394-400.

Tarkowski, A. K. (1971) Recent studies on parthenogenesis in the mouse. J. Reprod. Fert., Suppl. 14, 31-39.

Tarkowski, A. K. (1980) Fertilization of nucleate and anucleate fragments in the mouse. Expl Cell Res. 128, 73.

Toyoda, Y., Yokoyama, M. \& Hosi, T. (1971) Studies on the fertilization of mouse eggs in vitro. I. In vitro fertilization of eggs by fresh epididymal sperm. Jap. J. Anim. Reprod. 16, 147-151.

Usui, N. \& Yanagimachi, R. (1976) Behavior of hamster sperm nuclei incorporated into eggs at various stages of maturation, and early development. The appearance and disappearance of factors involved in sperm chromatin decondensation in egg cytoplasm. plasm. J. Ultrastruct. Res. 57, 276-288.

Whitten, W. (1971) Nutrient requirements for the culture of preimplantation embryos in vitro. Adv. Biosci. 6, 129-140.

Wolf, D.P. (1978) The block to sperm penetration in zona-free mouse eggs. Devl Biol. 64, 1-10.

Wolf, D.P., Inoue, M. \& Stark, R.A. (1976) Penetration of zona-free mouse ova. Biol. Reprod. 15, 213-221.

Yanagimachi, R. (1978) Sperm-egg association in mammals. Curr. Topics Devl Biol. 12, 83-105.

Received 6 October 1980 